\title{
A taxonomic revision of orthosternous scorpions from the English Coal Measures aided by x-ray micro-tomography (XMT)
}

\author{
David A. Legg, Russell J. Garwood, Jason A. Dunlop, and Mark D. Sutton
}

\begin{abstract}
Fossil scorpion systematics - particularly that of the diverse assemblage found in Carboniferous Coal Measure deposits - are problematic, being characterised by a large number of frequently monotypic taxa, based on a limited set of characters. These Palaeozoic scorpions have the potential to elucidate the nature of the scorpion stemgroup and hence to inform long running debates regarding the origin of the crown group and relationships between extant lineages. Carboniferous taxa are often found in siderite concretions and can be preserved in three dimensions. This study investigates two such fossils of the species Compsoscorpius buthiformis (Pocock, 1911) with the aid of X-ray Micro-Tomography (XMT) and computer reconstruction. These scans reveal important new details of the anatomy, such as the walking legs, that allow more detailed comparison with coeval taxa. Many of these taxa are revealed here to be junior synonyms of $C$. buthiformis and previous taxonomic practice, as it relates to Coal Measures scorpions, is criticised. The ecology of $C$. buthiformis is also reviewed in light of the new evidence from XMT. In particular, aspects of its walking leg and metastomal anatomy are analogous to that of extant lithophilic and 'errant' leaf-litter scorpions.
\end{abstract}

David A. Legg. Department of Earth Science and Engineering, Imperial College, London SW7 2AZ, UK, d.legg10@imperial.ac.uk

Russell J. Garwood. Manchester X-ray Imaging Facility, School of Materials, The University of Manchester, Oxford Rd., M13 9PL, UK, russell.garwood@ manchester.ac.uk

Jason A. Dunlop. Museum für Naturkunde, Leibniz Institute for Research on Evolution and Biodiversity at the Humboldt University Berlin, D-10115 Berlin, Germany, jason.dunlop@mfn-berlin.de Mark Sutton. Department of Earth Science and Engineering, Imperial College, London SW7 2AZ, UK, m.sutton@imperial .ac.uk

Keywords: Scorpiones; computed tomography; VAXML; terrestrialisation; carboniferous; siderite

\section{INTRODUCTION}

Scorpions are a diverse order of arachnids with over 1,947 described extant species (Prendini, 2011). There are currently also 120 fossil species recognised, derived from 133 published names
(Dunlop et al., 2012). Their fossil record extends back to the Silurian (Anderson, 2007), making them the oldest unequivocally known arachnids (Selden, 1993). On current data, there are - perhaps surprisingly - more fossil scorpion species 


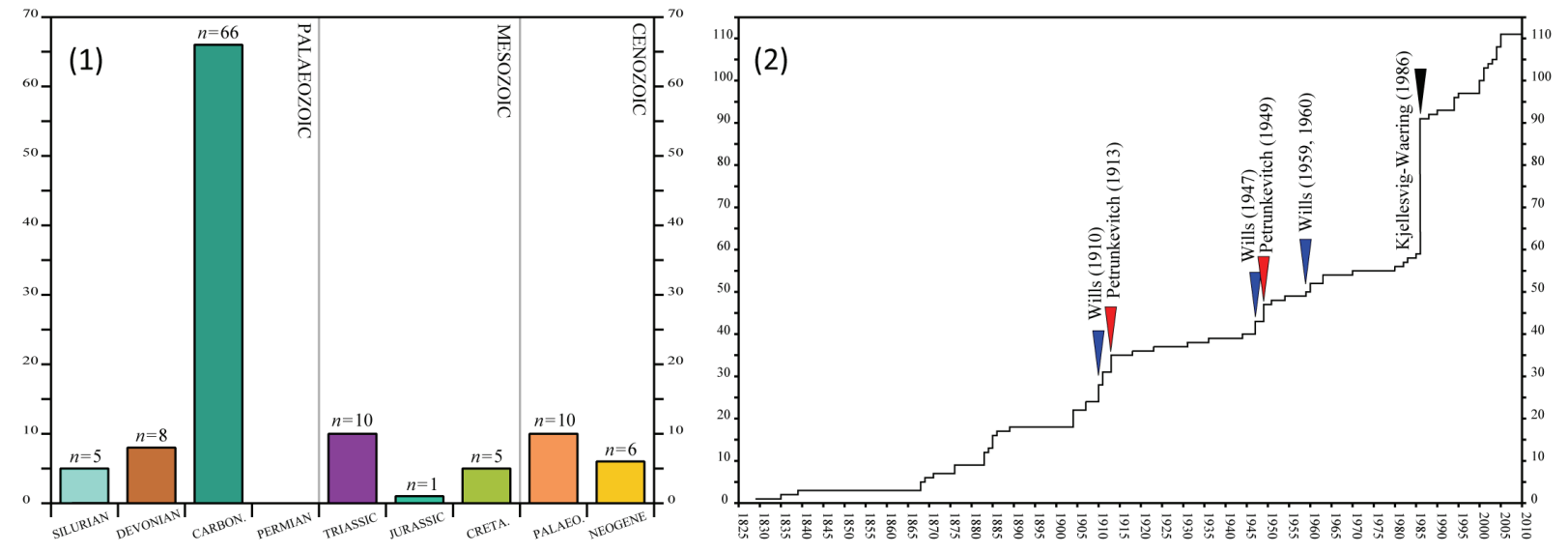

FIGURE 1. The diversity of fossil scorpions. (1) A histogram showing the temporal distribution of currently recognised fossil scorpion species; and (2) a collector curve showing the contribution of Leonard Wills, Alexander Petrunkevitch and Erik Kjellesvig-Waering, to current estimates of fossil scorpion diversity.

from the Palaeozoic Era than from the Mesozoic and Cenozoic Eras combined (Figure 1.1; Dunlop et al., 2008a), with the Carboniferous 'Coal Measures' being particularly species-rich. It is not clear to what extent this observation reflects genuine diversity; it may represent a sampling bias resulting from the existence of numerous scorpion-rich localities of late Palaeozoic age. An additional bias may come from taxonomic over-splitting - the majority of these species were recognised and described by only a handful of workers, e.g., Kjellesvig-Waering (1986) (Figure 1.2), and criticisms of earlier taxonomic practices have been raised (see, for example, Dunlop et al., 2008b).

Another point of controversy is that many Palaeozoic scorpions have been interpreted as aquatic (e.g., Kjellesvig-Waering, 1986; Selden and Jeram, 1989; but see Scholtz and Kamenz, 2006 for an alternative view). If scorpions were plesiomorphically aquatic it would imply that at least two terrestrialisation events occurred within crowngroup Arachnida; we therefore consider this issue to be of considerable significance.

Several recent studies (Garwood et al., 2009; Garwood and Sutton 2010) have demonstrated the efficacy of X-ray micro-tomography (XMT) in the study of siderite hosted fossils. Such preservation - often three-dimensional - is common in Carboniferous Lagerstätten. The traditional approach to studying these fossils (i.e., splitting the nodule) typically results in incomplete data recovery, whereas XMT and 'virtual palaeontology' can reveal the original three-dimensional morphology in full (Garwood et al., 2010). Here the technique is applied to siderite-hosted specimens of a phylogenetically important Carboniferous scorpion species, revealing previously unknown morphological features in an animal probably close to crown-group Scorpiones. In combination with restudy of a number of Coal Measures specimens using traditional techniques, this has allowed a taxonomic revision and we believe a more reliable interpretation of the species' palaeoecology.

\section{MATERIALS AND METHODS}

Numerous specimens from the Coseley and Sparth Bottoms Lagerstätten were examined and camera lucida drawings produced, using a Nikon binocular microscope with a drawing tube attached. Two specimens of Compsoscorpius buthiformis from the Natural History Museum, London were scanned (NHM I 5862 and I 7883). They originate from the Coseley Lagerstätte Clay-croft open-cast works (Staffordshire, UK), probably from the "10 foot ironstone measures" (Figure 2; Duckmantian, ca. 311Ma; Wilson, 2005). Both are preserved within siderite nodules as voids with partial kaolinite infills; I 7883 contains additional pyrite infill on the limbs. Previous studies have suggested Coseley's interbedded sandstones, mudstones, and coals represent a brackish to freshwater environment, possibly as part of a prograding delta complex (Wilson, 2005) or a lacustrine environment typical of a Coal Measure swamp forest (Braznell, 2006). The flora includes sphenopsids, ferns, pteridosperms, and lycopsids, and the fauna comprises xiphosurans, arachnids, millipedes, winged insects, crustaceans, cartilaginous jawed fishes, and bony fishes (Braznell, 2006). 


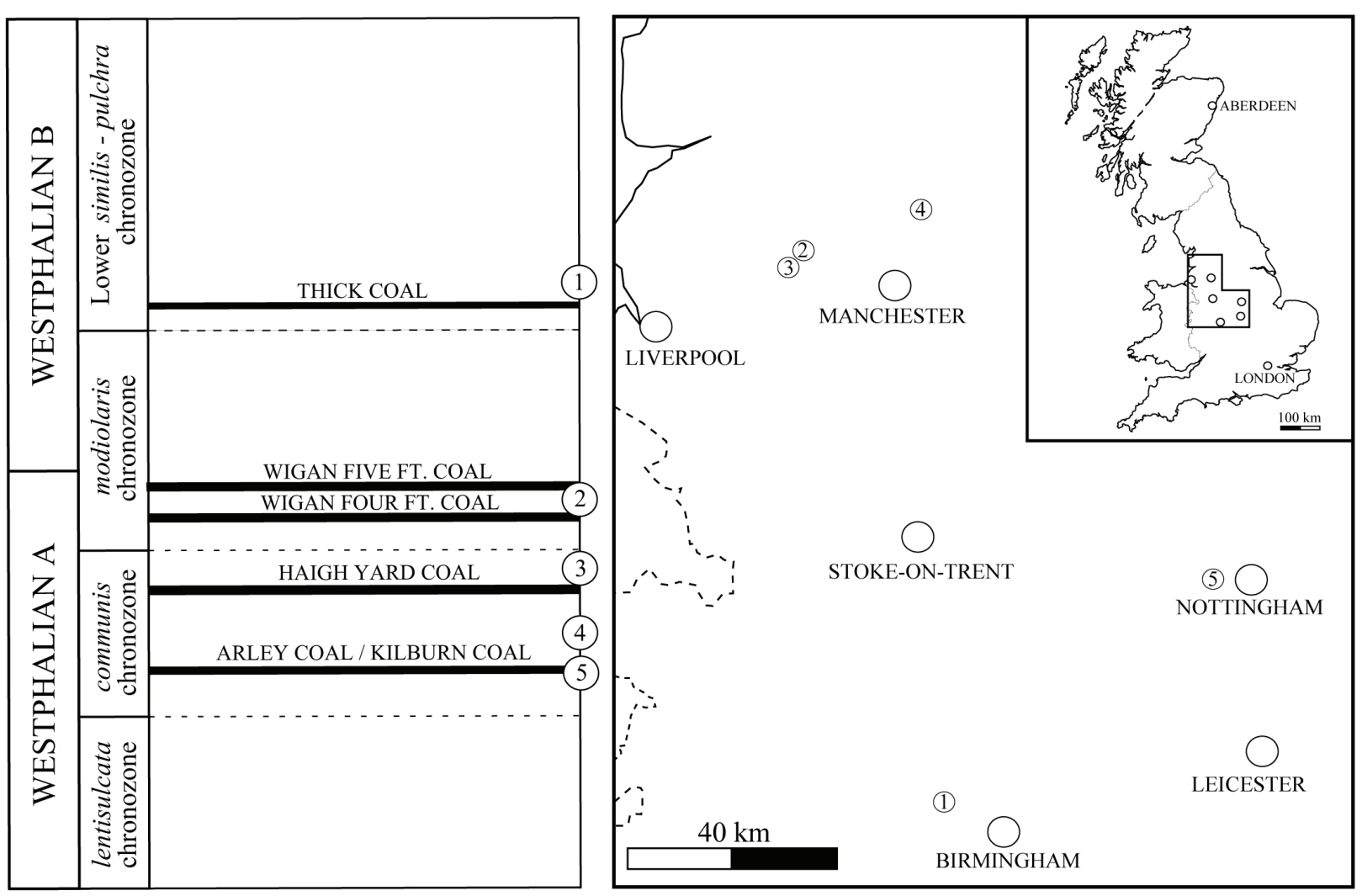

FIGURE 2. The temporal and geographical distribution of fossil scorpion bearing deposits in the British Midlands. Abbreviations: 1: Kilburn; 2: Sparth Bottoms; 3: Bickershaw; 4: Westhaughton; 5: Coseley.

Most work on the Sparth Bottoms locality (Lancashire, UK) is dated, and information is hence limited. The fossils are siderite hosted, as with Coseley, and the fossiliferous horizons occur within grey-blue shales (Baldwin and Sutliffe, 1904). Bolton (1920) suggested these represent true lagoon or swamp-pool deposits. The fossils were found within the communis Zone (Figure 2; Hansman, 1972) making them Langsettian, ca. 318-313 Ma in age (Ogg et al., 2008). The fauna includes insects and insect nymphs, annelids, arachnids, myriapods, crustaceans, a small number of fish, and a strong molluscan element (Schram, 1979). There do not appear to be any studies that have directly addressed the flora of the deposit.

Scans were conducted at the Natural History Museum, London on a Nikon X-Tek HMX-ST scanner using a tungsten reflection target and 3142 projections. I 5862 was scanned at $190 \mathrm{kV}$ and $160 \mu \mathrm{A}$ with no filter and an exposure of 0.25 seconds, I 7883 at $215 \mathrm{kV}$ and $180 \mu \mathrm{A}$ with a $1.5 \mathrm{~mm}$ copper filter and 0.25 second exposure. The 2000x2000 detector provided voxel sizes of $20 \mu \mathrm{m}$ (I 7883) and $14 \mu \mathrm{m}$ (I 5862). Reconstructed tomogram stacks were used to create interactive three-dimensional models in the custom SPIERS software suite (Sutton et al., 2002). Datasets were manually cleaned to remove artefacts and noise (e.g., cracks within the nodule); discrete structures (e.g., appendages) were identified for rendering in different colours. The raytracing application Blender (blender.org) was used to produce visualisations for publications. Note that some portions of the morphology were incompletely preserved but could be inferred; these are rendered as translucent. Animations of these models are available as online supplementary material (Video 1; Video 2). Furthermore, these specimens are included in the Supplementary Material (online) as downloadable virtual models, in VAXML format (Sutton et al. 2012; see also www.spiers-software.org). They are in the form of ZIP-archives which can be extracted to a folder. If SPIERS is installed, the model can be viewed by double-clicking on the respective .vaxml file. Despite the fact both have been filtered to reduce triangle counts, relatively low-performance systems may struggle to render the model.

Anatomical terminology largely follows Stahnke (1970), except for walking leg nomencla- 

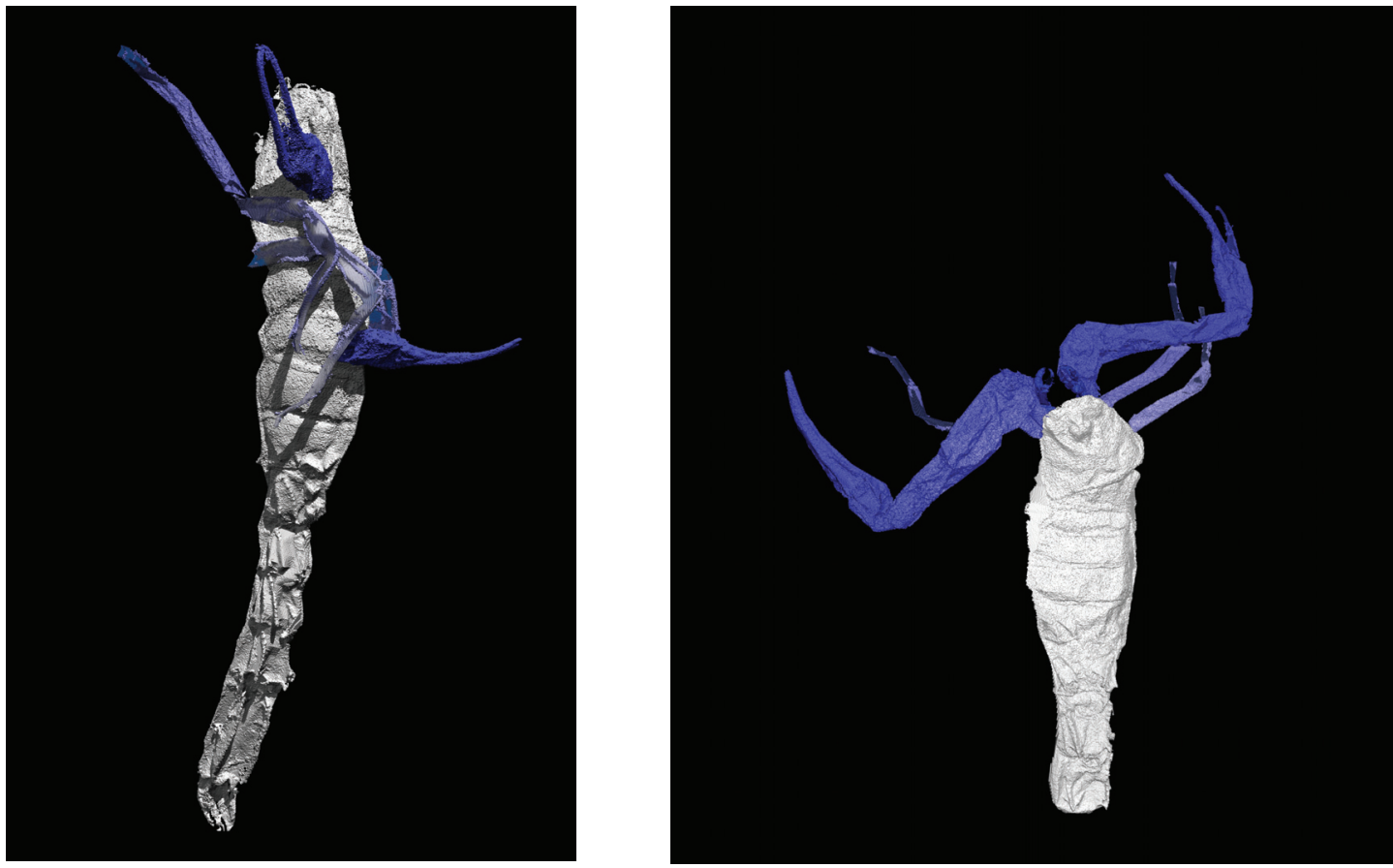

VIDEO 1. Digital visualisation of NHM 5862 (Compsoscorpius buthiformis). VIDEO 2. Digital visualisation of NHM 7883 (Compsoscorpius buthiformis).

ture which follows Couzijn (1976). The anterior, median, and posterior sections of the prosomal carapace are referred to as the propeltidium, mesopeltidium, and metapeltidium, respectively, in an attempt to standardise terminology between different arachnid orders (see e.g., Shultz, 2007).

\section{SYSTEMATIC PALAEONTOLOGY}

The higher systematics of fossil scorpions is a contentious issue (Dunlop et al., 2008b) and in particular the typological scheme proposed by Kjellesvig-Waering (1986) has been widely criticised. Pending a revision based on cladistic analysis, Compsoscorpius Petrunkevitch, 1949 has not been assigned here to any particular higher taxon. Jeram (1994) assigned it to the infraorder Orthosterni Pocock, 1911, and specifically the family Palaeopisthacanthidae Kjellesvig-Waering, 1986. However, since Jeram (1994, text-figure 1) resolved this family as paraphyletic we prefer not to use Palaeopisthacanthidae here.

Genus COMPSOSCORPIUS Petrunkevitch, 1949 1949 Lichnoscorpius Petrunkevitch, p. 148.

1949 Compsoscorpius Petrunkevitch, p. 149.

1953 Buthiscorpius Petrunkevitch, p. 32.

1986 Allobuthus Kjellesvig-Waering, p. 65.
1986 Allobuthiscorpius Kjellesvig-Waering, p. 105. 1986 Coseleyscorpio Kjellesvig-Waering, p. 113. 1986 Leioscorpio Kjellesvig-Waering, p. 209.

1986 Pseudobuthiscorpius Kjellesvig-Waering, p. 219.

Type species. Compsoscorpius elegans Petrunkevitch, 1949, by original designation; treated here as a junior synonym of $C$. buthiformis (Pocock, 1911) which is the only species now recognised in the genus.

Stratigraphical range and distribution. Upper Carboniferous (Langstettian to Duckmantian) of the English Midlands, UK.

Diagnosis. Distinguished from all other scorpions, both extinct and extant, by the following combination of characters: carapace with a rounded anterior margin; medial eye node located intramarginally; sternum subpentagonal with deep postero-medial sulcus; first pair of coxapophyses subtriangular, second pair of coxapophyses slender and rod shaped; walking legs with superior and inferior keel; genital opercula lacrimiform; mesosomal tergites tuberculate with anterior transverse process, lateral margins of mesosomal tergites I-V rounded; sixth mesosomal tergite with posterolateral carinae; metasoma segments with prominent 
dorsal carinae, ending in spine-like projections; fifth metasomal segment more than twice as long as fourth (emended from Jeram, 1994).

Remarks. The diagnosis of this genus has been emended to comply with observations made herein. Previous diagnoses were found to be inadequate as they lacked sufficient features to distinguish the taxon from other genera (e.g., KjellesvigWaering, 1986) or were based on characters that could not be distinguished in non-macerated specimens (e.g., Jeram, 1994).

Compsoscorpius buthiformis

(Pocock, 1911) comb. nov.

v. 1911 Anthracoscorpio buthiformis Pocock, p. 24-28, fig. 6-8, PI. 1, fig. 2, 2a, PI. 2, fig. 1.

1913 Eoscorpius buthiformis (Pocock); Petrunkevitch, p. 35.

v. 1949 Typhlopisthacanthus anglicus Petrunkevitch, p. 145, fig. 143, 182.

v. 1949 Lichnoscorpius minutus Petrunkevitch, p. 148-149, fig. 144, 145, 181.

v. 1949 Compsoscorpius elegans Petrunkevitch, p. 149-150, fig. 152-154, 183-185.

v. 1949 Compsoscorpius elongatus Petrunkevitch, pp. 150-151, fig. 147-150, 186-188.

1949 Eoscorpius buthiformis (Pocock); Petrunkevitch, p. 153.

1953 Anthracoscorpio miniutus (Petrunkevitch) Petrunkevitch, p. 30-31.

1953 Buthiscorpius buthiformis (Pocock); Petrunkevitch, p. 32, figs. 34, 45.

1953 Compsoscorpius elegans Petrunkevitch; Petrunkevitch, p. 32-33.

1953 Compsoscorpius elongatus Petrunkevitch; Petrunkevitch, p. 33.

1953 Typhlopisthacanthus anglicus Petrunkevitch; Petrunkevitch, p. 34.

1955 Buthiscorpius buthiformis (Pocock); Petrunkevitch, p. P74, fig. 43(3).

1955 Compsoscorpius elegans Petrunkevitch; Petrunkevitch, p. 75, fig. 44(1).

1960 Buthiscorpius buthiformis (Pocock), Wills, p. 277-290, pl. 46-48, text-fig. 1-9.

v. 1960 Buthiscorpius major Wills, p. 300-305, pl. 51, fig. 1-3, p. 52, text-fig. 14-16.

1962 Compsoscorpius elegans Petrunkevitch; Dubinin, p. 431, fig. 1235, 1253.
1962 Anthracoscorpio miniatus (Petrunkevitch); Dubinin, p. 431, fig. 1249.

1985 Buthiscorpius major (Wills); Selden, p. 6.

1985 Lichnoscorpius miniatus Petrunkevitch; Selden, p. 6.

1986 Buthiscorpius buthiformis (Pocock); Kjellesvig-Waering, p. 102-103, text-fig. 40, $110 \mathrm{~F}$

1986 Allobuthiscorpius major (Wills); KjellesvigWaering, p. 105-106.

1986 Lichnoscorpius miniatus Petrunkevitch; Kjellesvig-Waering, p. 110-112, text-fig. 45.

v. 1986 Allobuthus macrostethus Kjellesvig-Waering, p. 112-113, text-fig. 110C, 113B4.

v. 1986 Coseleyscorpio lanceolatus KjellesvigWaering, p. 113.

v. 1986 Leioscorpio pseudobuthiformis KjellesvigWaering, p. 209-210, text-fig. 92.

v. 1986 Pseudobuthiscorpius labiosus KjellesvigWaering, p. 219-220, text-fig. 97, 112J.

1986 Compsoscorpius elegans Petrunkevitch; Kjellesvig-Waering, p. 236-239, text-figs. 105-107.

1993 Allobuthiscorpius major (Wills); Selden, p. 303.

? 1994 Compsoscorpius elegans Petrunkevitch; Jeram, p. 530-536, text-figs. 3, 4A-C, E-G, 5A-J; Pls.

$1 ; 2$, figs. $1-7,10-13 ; 3$, figs. $1-10 ; 6$, figs. 4,$7 ; 7$, figs. 1-5.

2000a Compsoscorpius elegans Petrunkevitch; Fet, p. 424.

2000b Allobuthiscorpius major (Wills); Fet, p. 559.

2000b Allobuthus macrostethus Kjellesvig-Waering, Fet, p. 560.

2000b Coseleyscorpio lanceolatus KjellesvigWaering, Fet, p. 561.

2000b Lichnoscorpius miniatus Petrunkevitch; Fet, p. 562.

2000b Buthiscorpius buthiformis (Pocock); Fet, p. 562.

2000b Leioscorpio pseudobuthiformis KjellesvigWaering; Fet, p. 586.

2000 b Pseudobuthiscorpius labiosus KjellesvigWaering; Fet, p. 589. 


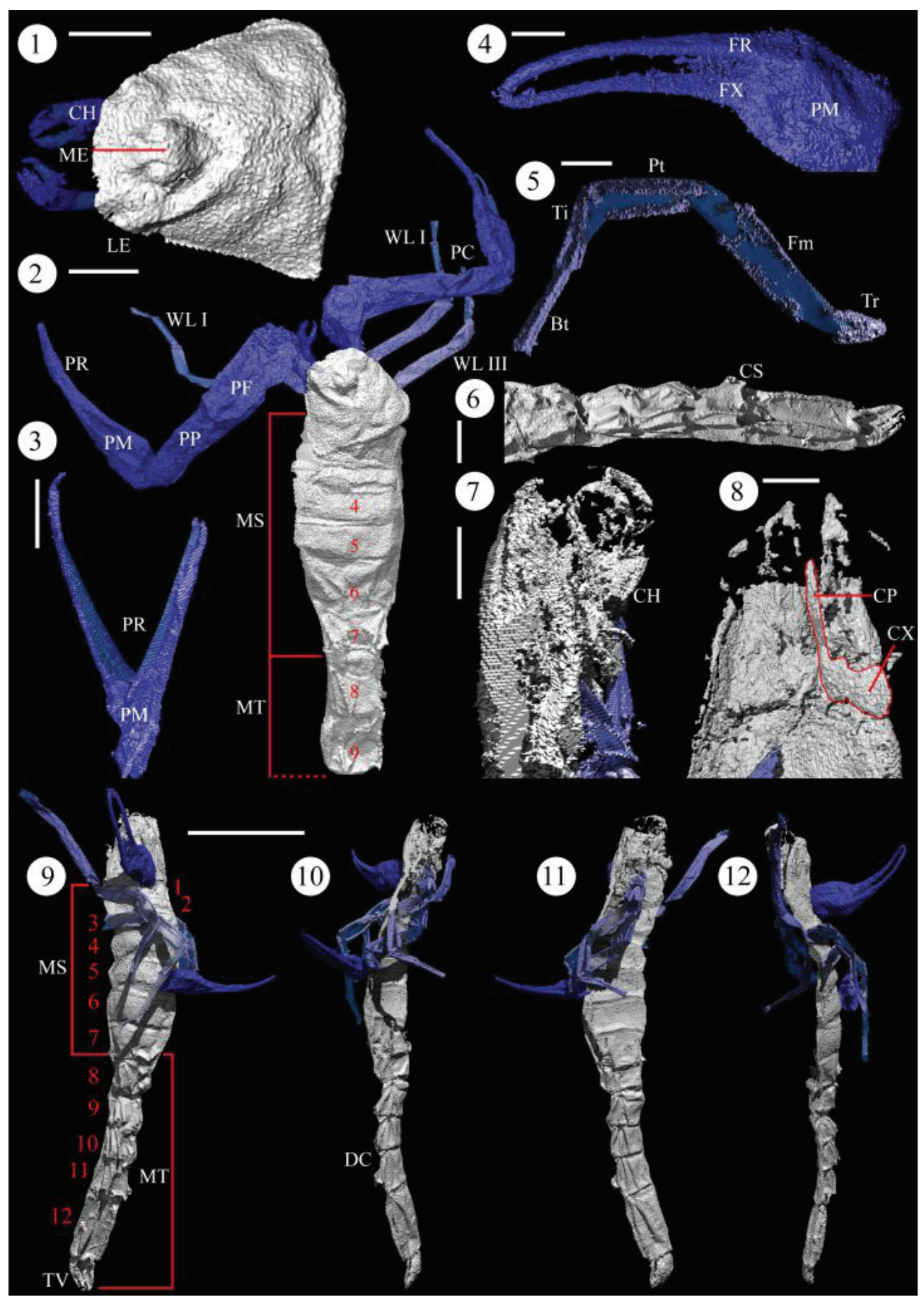

FIGURE 3. Digital visualisations of Compsoscorpius buthiformis. NMH I 7883: (1) detailed view of carapace and chelicerae, (2) entire specimen in dorsal view, and (3) lateral view of left pedipalp. NHM I 5862: (4) detail of pedipalp chela, (5) detailed view of a walking leg, (6) detailed view of the metasoma, (7) lateral view of prosoma, (8) ventral view of prosoma, (9) in dorsal view, (10) in right lateral view, (11) in ventral view, and (12) in left lateral view. Scale bars equal: (1,6,7) $2 \mathrm{~mm}$, (2) $5 \mathrm{~mm}$, (3) $3 \mathrm{~mm},(4,5,8) 1 \mathrm{~mm}$, and (9-12) $8 \mathrm{~mm}$. Abbreviations: Bt: basitarsus; $\mathrm{CH}$ : chelicerae; CP: coxapophysis; CS: carinal spine; CX: coxa; DC: dorsal carinae; Fm: femur; FR: free finger; FX: fixed finger; LE: lateral eye; ME: medial eye node; MS: mesosoma; MT: metasoma; PF: pedipalp femur; PM: pedipalp manus; PP: pedipalp patella; PR: pedipalp rami; Pt: patella; Ti: tibia; Tr: trochanter; TV: telson vesicle; WL: walking leg; and 1-12, segment number. See supplementary information for animations of these models. 
Holotype. NHM In 18596, by original designation.

Type locality and horizon. Carboniferous (Langstettian), Carbonicola communis beds, Middle British Coal Measures, Sparth Bottoms, Rochdale, Lancashire, England, UK.

Additional material. NHM I 7883 (holotype of Compsoscorpius elegans), I 5862 (holotype of Compsoscorpius elongatus), In 31261 (holotype of Typhlopisthacanthus anglicus), I 1555 (holotype of Pseudobuthiscorpius labiosus), In 22832 (holotype of Leioscorpio pseudobuthiformis), In 31262 (holotype of Coseleyscorpio lanceolatus), In 31266 (holotype of Lichnoscorpius minutus); BU 720 (holotype of Allobuthus macrostethus); and BGS Za 2926 (holotype of Allobuthiscorpius major). All specimens are from the Upper Carboniferous, Upper Coal Measures (Modiolaris similis - pulcha zone), near Coseley, Staffordshire, England, UK; except BGS Za 2926 which is from the Kilburn Coal, Trowell Colliery, Nottinghamshire, England, UK.

\section{Diagnosis. As for genus.}

Description. Scanned specimen of Compsoscorpius buthiformis, NHM I 7883. Near complete specimen (Figures 3.1-3.3). Carapace with rounded anterior margin, $6.9 \mathrm{~mm}$ long and $8.0 \mathrm{~mm}$ wide. Medial eye node located intramarginally, $1.7 \mathrm{~mm}$ from the anterior margin of the carapace. Demarcations between propeltidium and mesopeltidium; and mesopeltidium and metapeltidium present. Posterior margin of mesopeltidium contacts posterior margin of the carapace. Mesopeltidium divided by a medial sulcus. Carapace covered by numerous small pits, c. $10 \mu \mathrm{m}$ in diameter. Chelicerae present. Coxa of left chelicerae poorly preserved. Chelicera free finger falcate. Both pedipalps preserved; coxa, trochanter, femur, patella, and chela present. Proximal end of pedipalp coxa not preserved. Pedipalp trochanter $2.4 \mathrm{~mm}$ long. Pedipalp femur $6.1 \mathrm{~mm}$ long and covered by small pits, as is the patella. Patella with prominent keel, $5.3 \mathrm{~mm}$ long and $1.7 \mathrm{~mm}$ tall at its highest point. Pedipalp manus subtrapezoidal, $12.4 \mathrm{~mm}$ long, including fixed finger, and $3.0 \mathrm{~mm}$ wide, covered by numerous small pits. Chelal rami $8.8 \mathrm{~mm}$ long and slightly curved; tips are falcate. Dentition could not be observed. Walking legs poorly preserved; right walking leg I (?) and III (?) present; and left walking leg I (?). Proximal end of right walking leg I missing. Walking legs are laterally flattened. Walking leg femur $4.9 \mathrm{~mm}$ long, patella $3.5 \mathrm{~mm}$ long, tibia $2.6 \mathrm{~mm}$ long, basitarsus $1.6 \mathrm{~mm}$ long, and telotarsus $2.3 \mathrm{~mm}$ long. Mesosoma incompletely pre- served; tergite I missing. Mesosomal tergites increase in length posteriorly; mesosomal tergite III is $2.8 \mathrm{~mm}$ long, tergite VII is $5.3 \mathrm{~mm}$ long. Lateral margins of mesosomal tergites are rounded; anterior transverse ridges present. Postero-lateral carinae are present on the sixth and seventh tergite, and covered by coarse tubercles. Three metasomal somites present. Dorsal carinae present on metasomal somites. Carinae on metasomal somites end in prominent spines at the posterior margin of the somite.

Scanned specimen of Compsoscorpius buthiformis, NHM I 5862. Near complete specimen (Figures 3.4-3.12). Carapace with rounded anterior margin, $4.3 \mathrm{~mm}$ long and $4.1 \mathrm{~mm}$ wide. Medial eye node located intramarginally, $1.7 \mathrm{~mm}$ from anterior margin of the carapace. Lateral eyes located on the anterolateral margin; individual ocelli could not be observed. Demarcations between propeltidium and mesopeltidium; and mesopeltidium and metapeltidium present. Mesopeltidium divided by a medial sulcus. Coxae of chelicerae present but poorly preserved. Pedipalps incompletely preserved: coxa, trochanter, femur, and patella missing. Pedipalp chelae present; manus subtrapezoidal, rami slightly curved with falcate tips. Pedipalp chela, including fixed finger, $7.3 \mathrm{~mm}$ long, free finger $3.8 \mathrm{~mm}$ long. Elongate structure on the left anterior may be a walking leg or part of the pedipalp. Left and right walking legs III and IV present. Trochanter $1.3 \mathrm{~mm}$ long, femur $3.8 \mathrm{~mm}$ long, patella $2.5 \mathrm{~mm}$ long, tibia $1.8 \mathrm{~mm}$ long, basitarsus $1.7 \mathrm{~mm}$ long, and telotarsus $0.8 \mathrm{~mm}$ long, although possibly incomplete; podomeres vary little in length between walking legs. Superior and inferior keels present on podomeres, particularly on the walking leg patella. First pair of walking leg coxae preserved, $1.3 \mathrm{~mm}$ wide. Rod-like coxapophyses present. Seven mesosomal tergites present; total mesosomal length $12.1 \mathrm{~mm}$. Each mesosomal tergite possesses an anterior transverse ridge and rounded lateral margins. The sixth tergite is the widest at $4.8 \mathrm{~mm}$. Postero-lateral carinae are present on the sixth and seventh tergites, which are covered by coarse tubercles. All metasomal somites present. Metasomal somites increase in length posteriorly; somite I is $2.2 \mathrm{~mm}$ long, somite IV is $2.7 \mathrm{~mm}$ long, somite $V$ is $4.6 \mathrm{~mm}$, nearly twice as long as the preceeding segment. Dorsal and dorsal lateral carinae present. The dorsal carinae on metasomal somites I-IV end in prominent spiniform granule. The carinae on somite $\mathrm{V}$ are reduced. Telson vesicle present but poorly preserved; aculeus absent. 


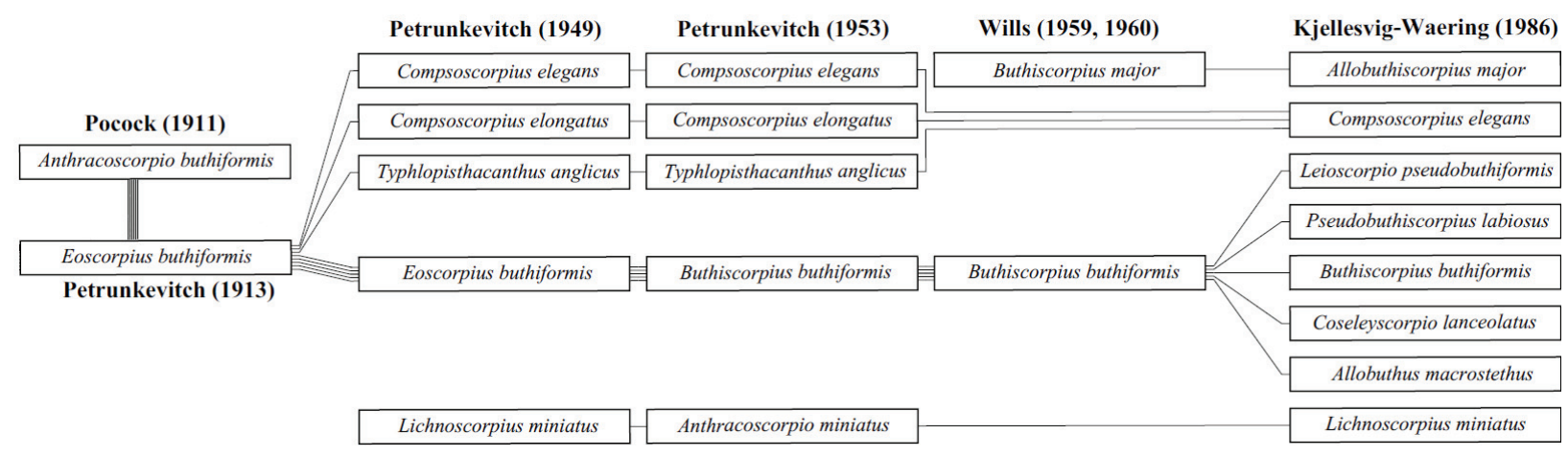

FIGURE 4. The taxonomic history of Compsoscorpius buthiformis comb. nov. Each line represents a specimen referred to $C$. buthiformis.

\section{Remarks and Synonymy}

Early work. The XMT results presented here allow detailed comparison with other Coal Measures scorpions known from a number of localities in the English Midlands (Figure 2). Many of these localities yielded scorpion specimens/species comparable to the scanned fossils NHM I 7883 and NHM I 5862 , which we consider all to be conspecific. Unfortunately previous work on these other species has been littered with taxonomic decisions that, in hindsight, may have been poorly justified and perhaps somewhat ill-judged; the taxonomic discussion that follows is hence somewhat tortuous and is summarised in Figure 4.

Compsoscorpius buthiformis (Pocock, 1911) was originally described by Pocock (1911) as Anthracoscorpio buthiformis; the genus Anthracoscorpio Kušta, 1885 having been previously raised for scorpions from the Coal Measures of Bohemia in the Czech Republic. Although Pocock did not formally diagnose his species, he noted a unique mesosomal ornamentation and slender pedipalp morphology. Pocock assigned a number of specimens to $A$. buthiformis including: NHM In 18596 (the Sparth Bottoms holotype), I 7883, I 1555, and In 22832. Note that Pocock (1911) also transferred another Sparth Bottoms scorpion to the genus as Anthracoscorpio sparthensis (Baldwin and Sutcliffe, 1904) and described a further species from Scotland in this genus as Anthracoscorpio dunlopi Pocock, 1911. A. sparthensis (now Eoscorpius sparthensis, sensu Kjellesvig-Waering, 1986), differs from $A$. buthiformis in the possession of an anteriorly located medial eye node and mesosomal tergites with straight lateral margins. $A$. dunlopi differs from $A$. buthiformis by the elongation of its carapace and the posterior deflection of the demarcations between the mesopeltidium and metapeltidium. A. sparthensis and A. dunlopi also lack granulation of the mesosomal tergites. For these reasons both species can be excluded from Compsoscorpius as we define it here. Resolution of their exact position is, however, beyond the scope of the present study and we retain them tentatively within Eoscorpius Meek and Worthen, 1868 and Anthracoscorpio, respectively.

Petrunkevitch's studies. Petrunkevitch (1913) interpreted Anthracoscorpio as a junior synonym of Eoscorpius transferring the three British species accordingly. Later, having studied the British fossils directly, Petrunkevitch (1949) assigned NHM I 7883 (formerly an A. buthiformis) to a new genus, Compsoscorpius. Together with NHM I 5862, they were designated the holotypes of $C$. elegans and $C$. elongates, respectively. According to Petrunkevitch (1949) these species could be distinguished by a parabolic rather than a semicircular carapace. In fact $C$. elegans and $C$. elongatus share a number of features that suggest they are conspecific, including granulation of the cuticle and prominent carinae on mesosomal tergites VI and VII (cf. Figures 3.3 and 3.9). The XMT scans also reveal that the carapace has been distorted in NHM I 5862 (Figures 3.9-3.12), possibly during ecdysis, and therefore this is not an adequate diagnostic criterion. Both Compsoscorpius elegans and C. elongatus are therefore here considered junior synonyms of $A$. buthiformis.

In the same monograph Petrunkevitch reinstated Anthracoscorpio for Kušta's Czech species and recognised another new British genus and species from Coseley, Lichnoscorpius minutus Petrunkevitch, 1949. This new taxon was distinguished from the, now supposedly blind, Anthracoscorpio by the presence of eyes. The type species of Anthracoscorpio, A. juvenis Kušta, 
1885, preserves very few diagnostic characters for meaningful comparison with Compsoscorpius, and may represent a juvenile specimen of a previously described Bohemian scorpion (DAL pers. ob.). Lichnoscorpius, on the other hand, possesses a number of features indicative of close affinities to Compsoscorpius. The mesosomal tergites of both Lichnoscorpius and Compsoscorpius are essentially identical; they possess a granular cuticle, an anterior transverse ridge and rounded lateral margins. Other features are hard to determine in $L$. minutus, for instance carinae on the mesosomal tergites could not be observed, and for this reason this species can only be tentatively assigned to Compsoscorpius.

Petrunkevitch (1953) eventually reassigned $A$. buthiformis to a new genus, Buthiscorpius Petrunkevitch, 1953, diagnosed on a rounded carapace formed from two lateral lobes. In this sense it was distinct from the supposedly semicircular carapace of Anthracoscorpio and the subtriangular, but anteriorly rounded carapace, described for Compsoscorpius. As previously mentioned, the carapace of NHM I 5862 (formerly C. elongatus) has been distorted, making carapace shape a poor criterion to distinguish between genera.

Wills' revisions. Wills $(1959,1960)$ undertook a detailed study of siderite hosted scorpions, including those from Coseley and Sparth Bottoms. This included a redescription of material assigned to Buthiscorpius buthiformis, descriptions of new material referable to this species, and description of a new taxon, Buthiscorpius major Wills, 1960; herein considered another junior synonym of $B$. buthiformis. Two new specimens, NHM In 31262 and $\mathrm{BU} 720$, were assigned to $B$. buthiformis. These specimens are significant in that they reveal important features of the ventral anatomy, e.g., abdominal plate morphology. The coxosternal regions of these specimens are identical to that of NHM I 1555 (part of Pocock's original buthiformis material; see above) (Figure 3.8) and thus support their referral to $B$. buthiformis. Wills also described a new species: $B$. major. This taxon was distinguished from $B$. buthiformis on the basis of its large size, nearly twice that of the latter. We consider size to be a poor character for taxonomy, particularly as the ontogeny of $B$. buthiformis remains poorly understood. No additional characters separating these taxa could be discerned; $B$. major is therefore considered a junior synonym of $B$. buthiformis.

Kjellesvig-Waering's monograph. In his posthumous monograph, Kjellesvig-Waering (1986) reviewed nearly all fossil scorpion taxa known at that time, including those from Coseley and Sparth Bottoms. He recognised seven species from Coseley, including four new ones, and four from Sparth Bottoms, including one new one. Many specimens previously assigned to $B$. buthiformis were designated as holotypes of new taxa, including: NHM In, 22832, Leioscorpio pseudobuthiformis KjellesvigWaering, 1986; NHM I 1555, Pseudobuthiscorpius labiosus Kjellesvig-Waering, 1986; NHM In, 31262,, Coseleyscorpio lanceolatus KjellesvigWaering, 1986; and BU 720, Allobuthus macrostethus Kjellesvig-Waering, 1986. Wills' Buthiscorpius major (see above) became the type species of a new genus Allobuthiscorpius. The reasons for removing Leioscorpio pseudobuthiformis from $B$. buthiformis were not clearly outlined by KjellesvigWaering (1986), although he did note differences from Pseudobuthiformis labiosus, another species previously referred to $B$. buthiformis. In particular, he considered the first pair of coxapophyses of $P$. labiosus semi-lunate and thus distinct from the rodlike coxapophyses of $L$. pseudobuthiformis. However, our restudy indicates that the coxapophyses of $P$. labiosus are actually rod-shaped (Figures 5.55.6), like those of $L$. pseudobuthiformis. We have been unable to identify any differences between $L$. pseudobuthiformis, P. labiosus, and B. buthiformis that could not be accounted for by preservational or (minor) intraspecific variation; indeed the walking legs of $L$. pseudobuthiformis are indistinguishable from those revealed by the XMT scans (Figure $3.5)$ in that both possess carinae and similar podomere proportions. For these reasons $L$. pseudobuthiformis and $P$. labiosus are considered junior synonyms of $B$. buthiformis. Both $C$. lanceolatus Kjellesvig-Waering, 1986; and A. macrostethus Kjellesvig-Waering, 1986, possess a coxasternal region indistinguishable from $P$. pseudobuthiformis. Since we treat the latter taxon as a junior synonym of $B$. buthiformis (see above) we consider $C$. lanceolatus and $A$. macrostethus to be junior synonyms of $B$. buthiformis too. As well as the previously named taxa, Kjellesvig-Waering (1986) described a new species from Sparth Bottom, Aspiscorpio eageri Kjellesvig-Waering, 1986. This species was placed in a new family, Allobuthiscorpiidae Kjellesvig-Waering, 1986, along with Allobuthiscorpius major, based on the configuration of the coxapophyses and the supposed absence of lateral compound eyes. The presence of an anteriorly placed medial eye node and a mucronous cuticle in $A$. eageri indicates these taxa are not closely related. $A$. eageri is thus 

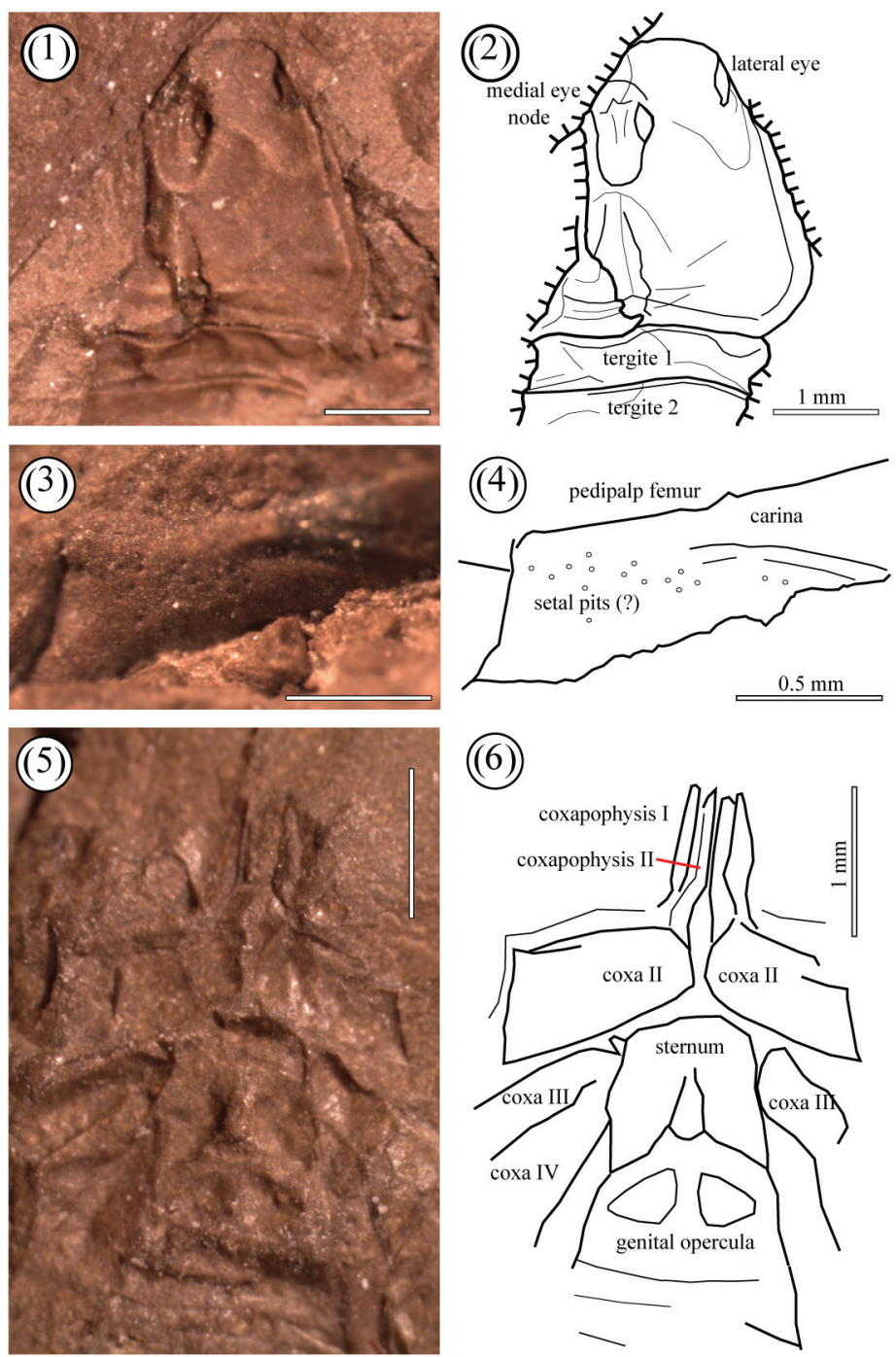

(6)
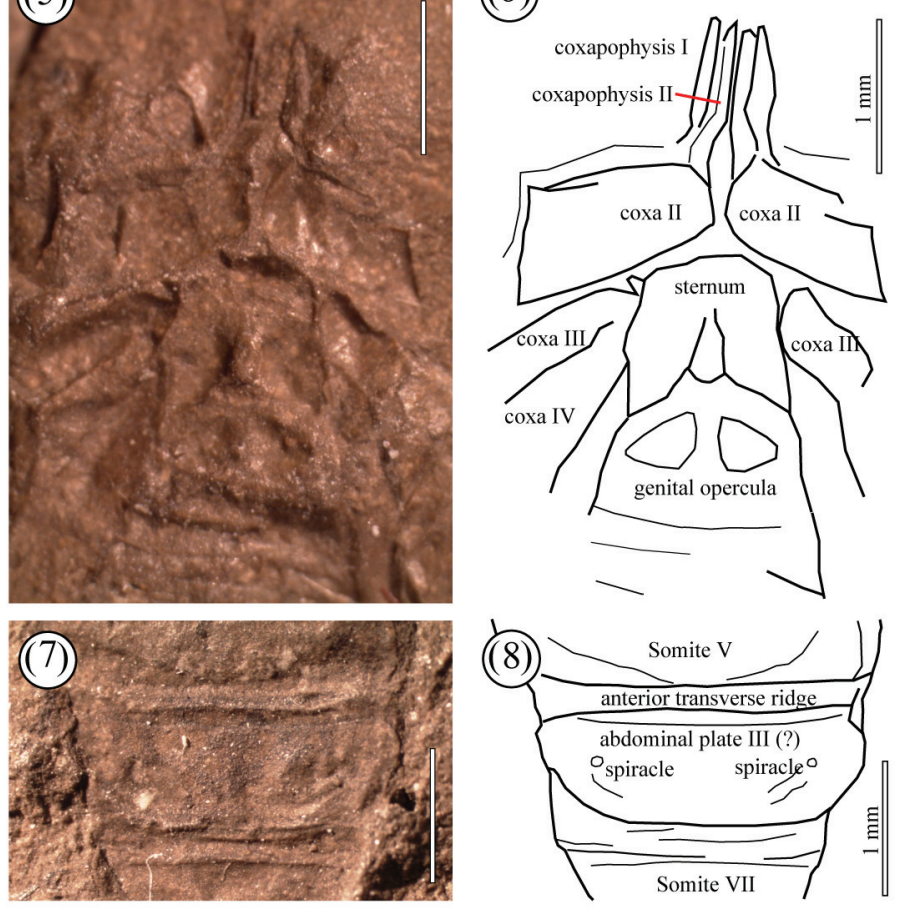

FIGURE 5. Detailed anatomy of Compsoscorpius buthiformis. 1 Photograph and 2 camera lucida drawing of the carapace of NHM I 5862; 3 photograph and 4 camera lucida drawing of the femur of NHM I 7883; 5 photograph and 6 camera lucida drawing of the coxasternal region of NHM I 1555; and 7 photograph and 8 camera lucida drawing of posterior mesosomal somites of NHM In 18596.

not a $B$. buthiformis synonym; its position will be addressed in later studies.

Later works. The most recent restudy of Compsoscorpius was undertaken by Jeram (1994), who studied cuticle fragments from coal and shale macerates. All English cuticle of a 'palaeopisthacanthid-type' was assigned to Compsoscorpius as, "the most parsimonious course of action" (Jeram
1994:518). However Jeram (1994) recorded a number of features, such as trichobothrial sockets, whose presence we have not been able to determine in the holotype of $C$. buthiformis. Other features, such as a secondary structure on the pedipalp chela, are apparently absent in $C$. buthiformis. While the possibility remains that these cuticle fragments are referable to a - per- 
haps unknown - species of Compsoscorpius, in the absence of further material we treat this assignment as tentative at best.

In summary, since Compsoscorpius elegans, the type species of Compsoscorpius, is (a) considered a junior synonym of $A$. buthiformis (see above) and since this taxon is (b) not referable to Anthracoscorpio and (c) Compsoscorpius, is a senior synonym of Buthiscorpius, the valid combination for this fairly abundant British Coal Measures scorpion taxon becomes Compsoscorpius buthiformis comb. nov. The various subsequently described taxa from Wills (1960) and KjellesvigWaering (1986) can also be assigned to this species as outlined above. Note that Lichnoscorpius Petrunkevitch, 1949 , is also a senior synonym of Buthiscorpius, however since the type material of this genus can only be tentatively assigned to this species, the genus name Compsoscorpius is preferred here.

\section{DISCUSSION}

\section{Cuticlular ornamentation}

The cuticle of $C$. buthiformis is granular (see for example Figure 3.1). A similar cuticular ornamentation has also been reported from other fossil scorpions previously referred to the Palaeopisthacanthidae, namely Palaeopisthacanthus Petrunkevitch, 1913; Cryptoscorpius Jeram, 1994; and Corniops Jeram, 1994. This ornamentation has hence been named 'palaeopisthacanthid-type' cuticle (Jeram, 1994). Many extant scorpions also possess a granular cuticle, e.g., Urodacus Peters, 1861. Koch (1981) noted that an increase in granulation and tuberculation in the latter species is typically associated with an increase in aridity. This relationship is expected is expected as an increase in surface texture would impede air flow over the cuticle, thereby reducing evaporation and water loss. Its presence in Compsoscorpius may thus represent a terrestrial adaptation, although the swampy palaeonenvironment inferred for the Coal Measures argues against this interpretation, and many extant species with granular ornamentation live in non-arid environments (Prendini, 2001).

\section{Eyes}

The medial eye-node of extant scorpions commonly sits near, or even behind, the centre of the carapace, whereas those of most Palaeozoic scorpions lie on or near the anterior margin. In this respect, $C$. buthiformis may represent an interesting intermediate condition; the medial eyes are sit- uated intramarginally. Significantly (and contrary to Petrunkevitch, 1953; and Kjellesvig-Waering, 1986), the lateral eyes of C. buthiformis do not appear to be divided into major and minor ocelli, the state in extant scorpions, instead there is an effaced region (Figures 5.1-5.2). This region is interpreted as an ocular membrane covering numerous ocelli - i.e., a compound eye. A similar region is present in other Palaeozoic scorpions (e.g., figures in Kjellesvig-Waering, 1986), although individual ocelli can rarely be distinguished.

The median eyes of stem-group scorpions are found in an anterior position on the carapace (Jeram, 1998), perhaps because visual sensilla originally contributed towards the detection of prey (Selden and Jeram, 1989). In modern scorpions these medial eyes are found toward the middle or posterior of the carapace as noted above, and serve largely to regulate the scorpions' circadian rhythm (Fleissner, 1977). Modern taxa are predominantly active at night, and detect prey largely through the use of trichobothria (see below) and other setae. The median eyes of $C$. buthiformis seem to document an evolutionary trend towards posterior displacement, as seen in the crown group, being found somewhat further back along the carapace compared to other fossils. This position may suggest less reliance on a visual system for prey capture, and perhaps even a shift towards a nocturnal mode of life. However, the presence here of compound lateral eyes suggests that vision was still of some importance for these animals.

\section{Trichobothria}

Trichobothria are sense organs, each consisting of long, thin hairs (the trich) that protrude from a cup-like cuticular cavity, known as a bothrium (Reissland and Görner, 1985). Trichobothria detect minor changes in air currents that aid in anemotaxic orientation and prey location (Krapf, 1986); their presence is therefore considered unequivocal evidence for a terrestrial habit (Selden and Jeram, 1989). The distribution and arrangement of trichobothria is variable amongst scorpion families, although relatively conservative within scorpion families (Vachon, 1974) and have therefore been considered an important indicator of systematic relationships (e.g., Soleglad and Fet, 2001). Trichobothria are rarely preserved in fossil scorpions, except in cases where they are preserved in amber, where their presence is usually inferred from the visible bothria. Bothria have been reported from a handful of Palaeozoic scorpions (Kjellesvig-Waering, 1986; Jeram, 1994), namely 
Palaeopisthacanthus, Cryptoscorpius, Corniops, and Compsoscorpius. These bothria were, however, identified from cuticular macerates and except in the case of Palaeopisthacanthus have not been observed on the holotype material, rendering assignment to Compsoscorpius equivocal. Resolution of the XMT scans in this study is too low to permit the identification of bothria, but an examination of NHM I 7883 revealed bothria-like structures on the dorsal surface of the pedipalp femur (Figures 5.3-5.4). These do not correspond to any (modern) diagnostic trichobothrial configuration, but provide additional evidence that Compsoscorpius buthiformis was terrestrial.

\section{Walking Legs and Coxapophyses}

The walking legs of $C$. buthiformis resemble those of extant scorpions and are clearly welladapted for terrestrial locomotion in that they are laterally flattened. This flattening is not an artefact of post-depostitional compaction, as it occurs irrespective of the limb's orientation in the matrix (Figures 3.9-3.12). Many Palaeozoic scorpions appear to possess rounded walking-leg podomeres (Kjellesvig-Waering, 1986), and the flattening of the walking legs is considered an adaptation for terrestrial locomotion (Størmer, 1963). The lateral compression of the limb strengthens the leg, thus allowing the scorpion to support its own weight outside of a fluid medium (Dalingwater, 1985). The degree of lateral compaction observed in the walking legs of $C$. buthiformis is comparable to that observed in extant lithophilic scorpions, e.g., Hadogenes troglodytes (Peters, 1861). In these taxa the lateral compaction allows them to manoeuvre in tight spaces (Eastwood, 1978). This alone is not evidence of a terrestrial habit, however, and a similar morphology has also been reported from various eurpyterids (Tollerton, 1989), although the possibility remains that these taxa were also terrestrial, or at least amphibious (Dalingwater, 1985). Unlike eurypterids, C. buthiformis possesses an elongate telotarsus - the tip of the leg which bears the claws - indicative of a plantigrade stance (Størmer, 1963) and thus implicitly of terrestrial locomotion (cf. Dunlop et al., 2008b).

The XMT scans reveal previously unknown details of the coxasternal region of $C$. buthiformis (Figure 3.8). Elongate rod-like coxapophyses are present on walking leg coxae I and II. In extant scorpions the coxapophyses form the base of a pre-oral chamber (the stomotheca), which is the site of extra-oral digestion in extant scorpions and other arachnids (Cohen, 1995). Extra-oral diges- tion cannot occur effectively in a fluid medium; the presence of a stomatheca is therefore further evidence for a terrestrial mode of life.

\section{Spiracles}

The mode of respiration in Palaeozoic scorpions is still a contentious issue and directly related to the issue of terrestrialisation (Scholtz and Kamenz, 2006 and references therein). The homology of the book-gills of horseshoe crabs (xiphosurans) and the book-lungs of arachnids has long been recognised (e.g., Van Beneden, 1871), and similarities between the book-lungs of scorpions and tetrapulmonates led Scholtz and Kamenz (2006) to propose a single terrestrialisation event, prior to the origin and diversification of the extant arachnid orders. However.the question of whether the first scorpions possessed xiphosuran-like book-gills or arachnid book-lungs, and by extension, whether they were aquatic, terrestrial, or amphibious (Jeram, 2001).

The book-gills of xiphosurans extend outwards from the ventral surface of their abdomen into the external environment; they can function in air but must be covered by a thin layer of fluid to function adequately (Reisinger et al., 1991). The gills are aerated by repeated extension and flexion of the abdominal plate muscles (Knudsen, 1973). Conversely the book-lungs of scorpions are internal, separated from the external environment by a sternite. Aeration is achieved by opening and closing the spiracles, slits in the sternites, also known as stigmata. Unequivocal, intramarginal spiracles are known from only a few Palaeozoic scorpions and are best seen in Palaeopisthacanthus schucherti (Vogel and Durden, 1966). Marginal spiracles along the posterior edge of the abdominal plates might have been present in other early scorpion taxa, but would be very difficult to detect in fossils.

Jeram (1994) assigned cuticular macerates bearing spiracles to Compsoscorpius, however the ventral anatomy of the mesosoma of Compsoscorpius is almost completely unknown and these fragments cannot be referred to this taxon with certainty. However our detailed re-examination of NHM In, 18596 has revealed structures we interpret as intramarginal spiracles (Figures 5.7-5.8). Only the dorsal side of this specimen is preserved, but ventral features are evident as a result of compressional approximation. This has resulted in the superimposition of the third abdominal plate into the sixth mesosomal tergite. Within this impression, two small circular impressions, $1 \mathrm{~mm}$ in diam- 
eter are evident. The bilateral symmetry of these structures (in position, size and shape) implies that they are not artefacts of preservation; their size and position are compatible with spiracles found in extant taxa. These structures provide yet more evidence of a terrestrial habit for $C$. buthiformis.

\section{Metasoma}

Like all scorpions, extinct and extant, $C$. buthiformis possesses a five-segmented metasoma tipped with a telson that is modified into a sting. The metasoma of $C$. buthiformis resembles extant scorpions in general form; successive somites increase in length posteriorly. The fifth metasomal somite is nearly twice as long $(4.6 \mathrm{~mm})$ and the preceding somite $(2.7 \mathrm{~mm})$. Although elongation of the fifth metasomal somite is common amongst extant scorpions it is most pronounced in those that use their sting more; for instance in Opisthacanthus lepturus (Beauvois, 1805), a species which stings very little (Heatwole, 1967), the ratio between the fourth and fifth somite is $1: 1.14$ (DAL pers. ob.), whereas in Tityus cambridgei Pocock, 1897, a species that stings frequently (Heatwole, 1967), there is a ratio of 1:1.67 (DAL pers. ob.), comparable to that of C. buthiformis, $1: 1.70$. Heatwole (1967) noted that scorpions that use their sting to subdue prey tend also to have more gracile pedipalp chelae, with chelal fingers much longer than the manus. This is also true of $C$. buthiformis (Figure 3.4), implying that it may have had a very powerful sting.

The XMT scans revealed the detailed morphology of the metasomal carinae for the first time (Figure 3.6). The metasomal carinae of $C$. buthiformis possess elongate spiniform granules on their posterior margins (Figure 3.6). In the extant scorpion Urodacus spines are most prominent in populations that live in arid environments (Koch, 1977) indicating they may be involved in water retention (Koch, 1981). In this regard they may behave like the carapace granulation by impeding air movement over the carapace, thereby reducing evaporation, although the same reservations regarding the Coal Measures palaeonenvironment apply. The metasomal somites of $C$. buthiformis are dorso-ventrally compressed (Figures 3.6 and 3.12). The lack of compression in other parts of the anatomy, e.g., the pedipalp claws, indicates that this is not a taphonomic artefact. Amongst extant species, a dorso-ventrally compressed metasoma tends to be found in species that exploit cracks and crevices amongst rocks or forest debris (Polis, 1990).

\section{CONCLUSIONS}

The evidence presented herein indicates that C. buthiformis was a terrestrial predator, like extant scorpions (Polis, 1990). Modern scorpions occupy a wide range of habitats from arid to humid. Polis (1990) recognised four general ecomorphotypes for scorpions; lithophilic, psammophilic, fossorial, and "errant"; each of which possesses a unique suite of adaptations suited to it habitat. Compsoscorpius buthiformis does not fit easily into any of these ecomorphotypes; it possesses a number of features in common with each group, as many extant "errant" scorpions do. We therefore consider it an errant scorpion. Errant scorpions typically live opportunistically in a variety of habitats, often in areas of rapid environmental change (McReynolds, 2008), e.g., leaf-litter. Compsoscorpius buthiformis possesses a number of features similar to those of extant leaf-litter inhabiting scorpions; e.g., Troglotayosicus humiculum Botero-Trujillo and Francke, 2009; such as a long, flattened metasoma and laterally compressed legs. These features are also common amongst lithophilic scorpions, however given the likely palaeoenvironment of the British Middle Coal Measures during the Late Carboniferous, we suggest that a leaf litter habitat is more probable.

Our taxonomic revision herein reduces the number of recognised species from Coseley to just three species: C. buthiformis, Cyclophthalmus robustus and Eoscorpius distinctus; and Sparth Bottoms to five species: Mazonia wardinleyi, Heloscorpio sutcliffei, Aspiscorpio eageri, ingleyi, and Eoscorpius sparthensis; this may still be an overestimation (Legg, 2009). Perhaps significantly, extant scorpions tend to have a higher diversity in desert areas, with four to 13 species per area, than in tropic areas, which tend to have less than five species per area (Polis, 1990). Other Palaeozoic deposits interpreted as having a similar palaeoenvironment, e.g., Mazon Creek, also have diverse scorpion faunas according to the current literature; re-investigation of these supposedly diverse faunas is thus overdue.

\section{ACKNOWLEDGEMENTS}

We would like to thank C. Mellish (NHM), J. Clatworthy (BU) and L. Neep (BGS) for access to materials. DAL would like to thank G. Edgecombe (NHM) for access to photographic equipment in his care and RG would like to thank R. Abel (NHM) for training in computed tomography techniques. DAL would also like to thank C. Kamenz (AMNH) for 
extensive discussion and the Palaeontological Association for providing Sylvester-Bradley funding to undertake this study. RG would like to acknowledge the assistance provided by the Manchester $X$-ray Imaging Facility, which was funded in part by the EPSRC (grants EP/F007906/1, EP/F001452/1 and $E P /(02249 X / 1)$.

\section{REFERENCES}

Abel, Richard Leslie, Laurini, Carolina Rettondini, and Richter, Martha 2012. A palaeobiologist's guide to 'virtual' micro-CT preparation. Palaeontologia Electronica Vol. 15, Issue 2;6T,17p; palaeo-electronica.org/content/issue-2-2012-technical-articles/233-micro-ct-workflow

Anderson, L.I. 2007. Unmineralised arthropods, p. 131156. In Clarkson, E.N.K., Harper, D.A.T., Taylor, C.M., and Anderson, L.I. (eds.), Silurian fossils of the Pentland Hills, Scotland. The Palaeontological Association, London.

Baldwin, W. and Sutliffe W.H. 1904. Eoscorpius sparthensis, sp. nov. from the Middle Coul-Measures of Lancashire. Quarterly Journal of the Geological Society, 60:394-399.

Bolton, H. 1921-1922. A monograph of the insect fossils of the British Coal-Measures. Palaeontographical Society Monograph.

Botero-Trujillo, R. and Francke, O.F. 2009. A new species of troglomorphic leaf litter scorpion from Columbia belonging to the genus Troglotayosicus (Scorpiones, Troglotayosicidae, p. 1-10. In Cokendolpher, J.C. and Reddell, J.R. (eds.), Texas Memorial Museum Speleological Monographs, 7; Studies on the cave and endogean fauna of North America, part V. Texas Memorial Museum and Texas Natural Science Center, University of Texas: Austin, Texas.

Braznell, L. 2006. Exceptional preservation in the Upper Carboniferous Coseley lagerstätte. Unpublished PhD Thesis, University of Birmingham, Birmingham, UK.

Cohen, A.C. 1995. Extra-oral digestion in predaceous Arthropoda. Annual review of Entomology, 40:85103.

Couzijin, H.W.C. 1976. Functional anatomy of the walking-legs of Scorpionida with remarks on the terminology and homologization of leg segments. Netherlands Journal of Zoology, 26:453-501.

Dalingwater, J.E. 1985. Biomechanic approaches to eurypterid cuticle and chelicerate exoskeletons. Transactions of the Royal Society of Edinburgh, 76:359-364.

Dubinin, V.B. 1962. Scorpionida. In Handbook of the palaeontology and geology of the USSR (Arthropoda: Tracheata and Chelicerata), 4:423-433. (Published in Russian as "Osnovy paleontologii", Moscow: Gosudarstvennoe Nauchno-Tekhnicheskoe Izdatel'stovo po Geologii i Okhrane Nedr)
Dunlop, J.A., Penney, D., and Jekel, D. 2012. A summary list of fossil spiders and their relatives. In Platnick, N.I. (ed.), The World Spider Catalogue, Version 12.5. The American Museum of Natural History, New York.

Dunlop, J.A., Tetlie, O.E., and Prendini, L. 2008b. Reinterpretation of the Silurian scorpion Proscorpius osborni (Whitfield): Integrating data from Palaeozoic and Recent scorpions. Palaeontology, 51:303-320.

Dunlop, J.A., Penney, D., Tetlie, O.E., and Anderson, L.I. 2008a. How many species of fossil arachnids are there? The Journal of Arachnology, 36: 267-272.

Eastwood, E.B. 1978. Notes on the scorpion fauna of the Cape. Part 3. Some observations on the distribution and biology of scorpions on Table Mountain. Annals of the South African Museum, 74:229-248.

Fet, V. 2000a. Family Palaeopisthacanthidae KjellesvigWaering, 1986, p. 424-425. In Fet,V., Sissom, W.D., Lowe, G., and Braunwalder, M.E. (eds.), Catalog of the scorpions of the world (1758-1998). The New York Entomological Society, New York.

Fet, V. 2000b. Suborder Branchioscorpionina KjellesvigWaering, 1986, p. 554-595. In Fet,V., Sissom, W.D., Lowe, G., and Braunwalder, M.E. (eds.), Catalog of the scorpions of the world (1758-1998). The New York Entomological Society, New York,.

Fet, V., Sissom, W.D., Lowe, G., and Braunwalder, M.E. 2000. Catalog of the scorpions of the world (17581998). The New York Entomological Society, New York.

Fleissner, G. 1977. Scorpion lateral eyes: Extremely sensitive receptors of zeitgeber stimuli. Journal of Comparative Physiology A, 118:101-108.

Garwood, R. and Sutton, M.D. 2010. X-ray micro-tomography of Carboniferous stem-Dictyoptera: New insights into early insects. Biology Letters 6:699-702

Garwood, R.J., Dunlop, J.A., and Sutton, M.D. 2009. High-fidelity X-ray mirco-tomography reconstruction of siderite-hosted Carboniferous arachnids. Biology Letters, 5:841-844.

Garwood, R.J., Rahman, I.A., and Sutton, M.D. 2010. From clergymen to computers - the advent of virtual palaeontology. Geology Today, 26: 96-100.

Hansman, R.H. 1972. Camptophyllia from the Lower Coal Measures of Lancashire. Journal of Paleontology, 46:315-320.

Heatwole, H. 1967. Defensive behaviour of some Panamanian scorpions. Caribbean Journal of Science, $7: 15-17$

Jeram, A.J. 1994. Carboniferous Orthosterni and their relationship to living scorpions. Palaeontology, 37:515-550.

Jeram, A.J. 1998. Phylogeny, classification and evolution of Silurian and Devonian scorpions. p. 17-31. In Selden, P.A. (ed.), Proceedings of the $17^{\text {th }}$ European Colloquium of Arachnology, Edinburgh, 1997. The British Arachnological Society, Burnham Beeches. 
Jeram, A. J. 2001. Palaeontology. p. 370-392. In Brownell, P. and Polis, G.A. (eds.), Scorpion Biology and Research. Oxford University Press, Oxford.

Kjellesvig-Waering, E.N. 1986. A restudy of the fossil Scorpionida of the world. Palaeontographica Americana, 55:1-287.

Knudsen, E.I. 1973. Muscular activity underlying ventilation and swimming in the horseshoe crab. Limulus polyphemus (Linnaeus). The Biological Bulletin, 144:355- 367.

Koch, L.E. 1977. The taxonomy, geographic distribution and evolutionary radiation of Australo-Papuan scorpions. Records of the Western Australian Museum, 5:83-367.

Koch, L.E. 1981. The scorpions of Australia: aspects of their ecology and zoogeography, p. 875-884. In Keast, A. (ed.), Ecological biogeography of Australia, 41(2).

Krapf, D. 1986. Verhaltensphysiologische Untersuchungen zum Beutefang von Skorpionen mit besonderer Berücksichtigung der Trichobothrien. Unpublished PhD thesis, University of Würzburg, Würzburg, Germany.

Kušta, J. 1885. Neue fossile Arthropoden aus dem Noeggerathienschiefer von Rakonitz. Sitzungsberichte der königlich Böhmischen Gesellschafter der Wissenschaften, Mathematisch-naturwissenschaftliche Classe. 1885:398-403.

Legg, D.A. 2009. The problem with Praearcturs: resolving basal scorpion relationships. Unpublished MSc thesis, University of Bristol, Bristol, UK.

McReynolds, C.N. 2008. Microhabitat preferences from the errant scorpion, Centruroides vittatus (Scorpiones, Buthidae). The Journal of Arachnology, 36:557-564.

Meek, F.B. and Worthen, A.H. 1868. Preliminary notice of a scorpion, a Eurypterus? and other fossils from the Coal Measures of Illinois and lowa. American Journal of Science and Arts, 45:25.

Ogg, J.G., Ogg, G., and Gradstein, F.M. 2008. The Concise Geologic Time Scale. Cambridge University Press, Cambridge.

Petrunkevitch, A. 1913. A monograph of the terrestrial Palaeozoic Arachnida of North America. Transactions of the Connecticut Academy of Arts and Sciences, 18:1-137.

Petrunkevitch, A. 1949. A study of Palaeozoic Arachnida. Transactions of the Connecticut Academy of Arts and Sciences, 37:69-315.

Petrunkevitch, A. 1953. Palaeozoic and Mesozoic Arachnida of Europe. Memoirs of the Geological Society of America, 53:1-122.

Pocock, R.I. 1911. A monograph of the terrestrial Carboniferous Arachnida of Great Britain. Monograph of the Palaeontographical Society, 64:1-84.
Polis, G.A. 1990. Ecology. p. 247-293. In Polis, G.A. (ed.), The Biology of Scorpions. Stanford University Press, Stanford.

Prendini, L. 2001. Substratum specialization and speciation in southern African scorpions: the Effect Hypothesis revisited, p. 113-138. In Fet, V. and Selden, P.A. (eds.), Scorpions 2001. In Memoriam Gary A. Polis. British Arachnological Society, Burnham Beeches.

Prendini, L. 2011. Order Scorpiones C.L. Koch. 1850. In: Zhang, Z.-Q. (Ed.) Animal biodiversity: An outline of higher-level classification and survey of taxonomic richness. Zootaxa, 3148: 115-117.

Reisinger, P.W.M., Tutter, I., and Welsch, U. 1991. Fine structure of the horseshoe crab Limulus polyphemus and Tachyplus tridentatus and of the book lung of the spider Eurypelma californicum, 1871. Zoologisches Jahrbuch der Anatomie, 121:331-357.

Reissland, A. and Görner, P. 1985. Trichobothria. p. 138161. In Barth, F.G. (ed.), Neurobiology of Arachnids. Springer, Berlin.

Scholtz, G. and Kamenz, C. 2006. The book-lungs of Scorpiones and Tetrapulmonata (Chelicerata: Arachnida): evidence for homology and a single terrestrialisation event of a common arachnid ancestor. Zoology, 109:2-13.

Schram, F.R. 1979. British Carboniferous Malacostraca. Fieldiana, 40: 1-129.

Selden, P.A. 1985. A shoe-box in a cellar in Rochdale (British fossil scorpions). Newletter of the British Arachnological Society, 44:6-7.

Selden, P.A. 1993. Arthropoda (Aglaspidida, Pycnogonida and Chelicerata), p. 297-320. In Benton, M.J. (ed.), The Fossil Record 2. Chapman and Hall, London.

Selden, P.A. and Jeram, A.J. 1989. Palaeophysiology of terrestrialisation in the Chelicerata. Transactions of the Royal Society of Edinburgh: Earth Sciences, 80:303-310.

Shultz, J.W. 2007. A phylogenetic analysis of the arachnid orders based on morphological characters. Zoological Journal of the Linnean Society, 150:221-265.

Soleglad, M.E. and Fet, V. 2001. Evolution of scorpion orthobothriotaxy - a cladistic approach. Euscorpius, 1:1-38.

Stahnke, H.L. 1970. Scorpion nomenclature and mensuration. Entomological News, 81: 279-316.

Størmer, L. 1963. Gigantoscorpio willsi, a new scorpion from the Lower Carboniferous of Scotland and its associated preying microorganisms. Skrifter Utgitt av Det Norske Videnskaps-Akademi I Oslo I. Mathematisk-Naturvidenskabelig Klasse. New series, 8:1-171.

Størmer, L. 1976. Arthropods from the Lower Devonian (Lower Emsian) of Alken an der Mosel, Germany. Part 5. Myriapods and additional forms, with general remarks on the fauna and problems regarding invasion of land by arthropods. Senckenbergiana Lethaea, 57:87-183. 
Sutton, Mark D., Garwood, Russell J., Siveter, David J., and Siveter, Derek J. 2012. SPIERS and VAXML; A software toolkit for tomographic visualisation and a format for virtual specimen interchange. Palaeontologia Electronica Vol. 15, Issue 2;5T,14p;

palaeo-electronica.org/content/94-issue-2-2012technical-articles/226-ct-toolkits

Tollerton, V.P. 1989. The morphology, taxonomy and classification of the order Eurypterida Burmeister, 1843. Journal of Paleontology, 63:643-657.

Vachon, M. 1974. Étude des caractères utilisés pour classer les famille et les genres de Scorpions (Arachnides). 1. Trichobothriotaxie en arachnologie. Sigles trichobothriaux et types de trichobothriotaxie chez les Scorpions. Bulletin du Muséum national d'Historie naturelle, 4:143-160.

Van Beneden, E. 1871. [No title]. Annals of the Entomological Society of Belgium, 1871: 9-11.
Vogel, B.R. and Dursden, C.J. 1966. The occurrence of stigmata in a Carboniferous scorpion. Journal of Paleontology, 40: 655-658.

Wills, L.J. 1910. On the fossiliferous Lower Keuper rocks of Worchestershire, with descriptions of the plants and animals discovered therein. Proceedings of the Geological Association, 21:249-331.

Wills, L.J. 1947. A monograph of British Triassic scorpions. Palaeontographical Society Monograph, 101:75-137.

Wills, L.J. 1959. The external anatomy of some Carboniferous "scorpions." Part 1. Palaeontology, 1:261-282.

Wills, L.J. 1960. The external anatomy of some Carboniferous "scorpions." Part 2. Palaeontology, 3:276-332.

Wilson, H.W. 2005. A new genus of archipolypodan millipede from the Coseley Lagerstätte. Palaeontology, 48:1097-1100. 